\title{
Different processes lead to similar patterns: a test of codivergence and the role of sea level and climate changes in shaping a southern temperate freshwater assemblage
}

\author{
Brian R Barber ${ }^{1 *}$, Peter J Unmack', Marcos Pérez-Losada ${ }^{1,2}$, Jerald B Johnson ${ }^{1,3}$ and Keith A Crandall1,3
}

\begin{abstract}
Background: Understanding how freshwater assemblages have been formed and maintained is a fundamental goal in evolutionary and ecological disciplines. Here we use a historical approach to test the hypothesis of codivergence in three clades of the Chilean freshwater species assemblage. Molecular studies of freshwater crabs (Aegla: Aeglidae: Anomura) and catfish (Trichomycterus arealatus: Trichomycteridae: Teleostei) exhibited similar levels of genetic divergences of mitochondrial lineages between species of crabs and phylogroups of the catfish, suggesting a shared evolutionary history among the three clades in this species assemblage.

Results: A phylogeny was constructed for Trichomycterus areolatus under the following best-fit molecular models of evolution GTR + I + R, HKY + I, and HKY for cytochrome b, growth hormone, and rag 1 respectively. A GTR + I $+\mathrm{R}$ model provided the best fit for both $28 \mathrm{~S}$ and mitochondrial loci and was used to construct both Aegla phylogenies. Three different diversification models were observed and the three groups arose during different time periods, from 2.25 to 5.05 million years ago (Ma). Cladogenesis within Trichomycterus areolatus was initiated roughly 2.25 Ma (Late Pliocene - Early Pleistocene) some 1.7 - 2.8 million years after the basal divergences observed in both Aegla clades. These results reject the hypothesis of codivergence.
\end{abstract}

Conclusions: The similar genetic distances between terminal sister-lineages observed in these select taxa from the freshwater Chilean species assemblage were formed by different processes occurring over the last 5.0 Ma. Dramatic changes in historic sea levels documented in the region appear to have independently shaped the evolutionary history of each group. Our study illustrates the important role that history plays in shaping a species assemblage and argues against assuming similar patterns equal a shared evolutionary history.

Keywords: Aegla, biogeography, Chile, cladogenesis, freshwater, Trichomycterus

\section{Background}

Understanding how species assemblages have been formed and maintained is a central question in biology [1-4]. Historical processes, such as river capture and climate change, likely played significant roles in driving the formation of aquatic species assemblages [5-7], whereas ecological processes may help maintain species interactions in co-occurring species if in fact those species are

\footnotetext{
* Correspondence: brbarber76@gmail.com

'Evolutionary Ecology Laboratories, Department of Biology, Brigham Young University, Provo, UT 84602 USA

Full list of author information is available at the end of the article
}

interacting (i.e form a community). Understanding the relative roles these two processes have had in shaping species assemblages or communities is challenging [8]. A logical first-step, especially in poorly studied regions, is to apply historical methods to understand how past events have shaped current patterns [9]. In this study we apply comparative phylogeography and biogeography methods $[10,11]$ to test the hypotheses that historical abiotic events are responsible for generating the pattern of similar levels of genetic divergence recently observed in two diverse taxa (three clades) that are codistributed in freshwater systems of Chile.

\section{C) Biomed Central}


Freshwater systems in Chile are biogeographically unique and were likely impacted by changes in sea levels (Figure 1). High gradient rivers originate in the Andes Mountains (1000 - $7000 \mathrm{~m}$ above sea level) then flow westward to the Pacific Ocean, a distance of only 100 $220 \mathrm{~km}$ [12]. Currently, most Chilean rivers are quite isolated from each other with the most likely colonization routes between them are across drainage divides or via coastal seas [13]. Gene flow between drainages could have occurred if rivers coalesced on the continental shelf during historical periods of low sea levels. However, the continental shelf is narrow, only $10-60 \mathrm{~km}$, providing limited opportunity for rivers to coalesce during lowered sea levels [13]. We predict divergence between populations would occur when sea levels are high, because the already restricted freshwater systems would have been truncated even more, thereby facilitating genetic drift and the accumulation of genetic divergence. In contrast, incipient divergence would have been erased when admixture occurred during lowered sea levels because previously isolated populations were merged. Overall, dramatic fluctuations in sea level should alter cladogenic rates. In addition, Late Pleistocene climate changes might have altered cladogenic rates due to changes in stream flow patterns and volume that altered the distribution of these organisms.

Compared to the Northern Hemisphere, relatively few phylogeographic or phylogenetic studies have been undertaken in southern latitudes, especially in temperate freshwater ecosystems [14]. However, phylogeographic and phylogenetic studies of terrestrial and freshwater taxa in Chile and Argentina $[15,16]$ are beginning to provide insights into the evolutionary history of this important region. Because aquatic diversity in Chile is relatively depauperate $[17,18]$ examination of a few widespread can provide important insights into the evolutionary history of the region. For example, a phylogenetic study of freshwater crabs in the genus Aegla (Aeglidae: Anomura; $[19,20]$ and a phylogeographic study of the freshwater catfish (Trichomycterus areolatus: Trichomycteridae: Teleostei; [13] discovered similar levels of model-corrected genetic distance of mitochondrial lineages between Aegla (cytochrome oxidase I and II genes: 1598 base pairs) and Trichomycterus (cytochrome b: 1137 base pairs). For

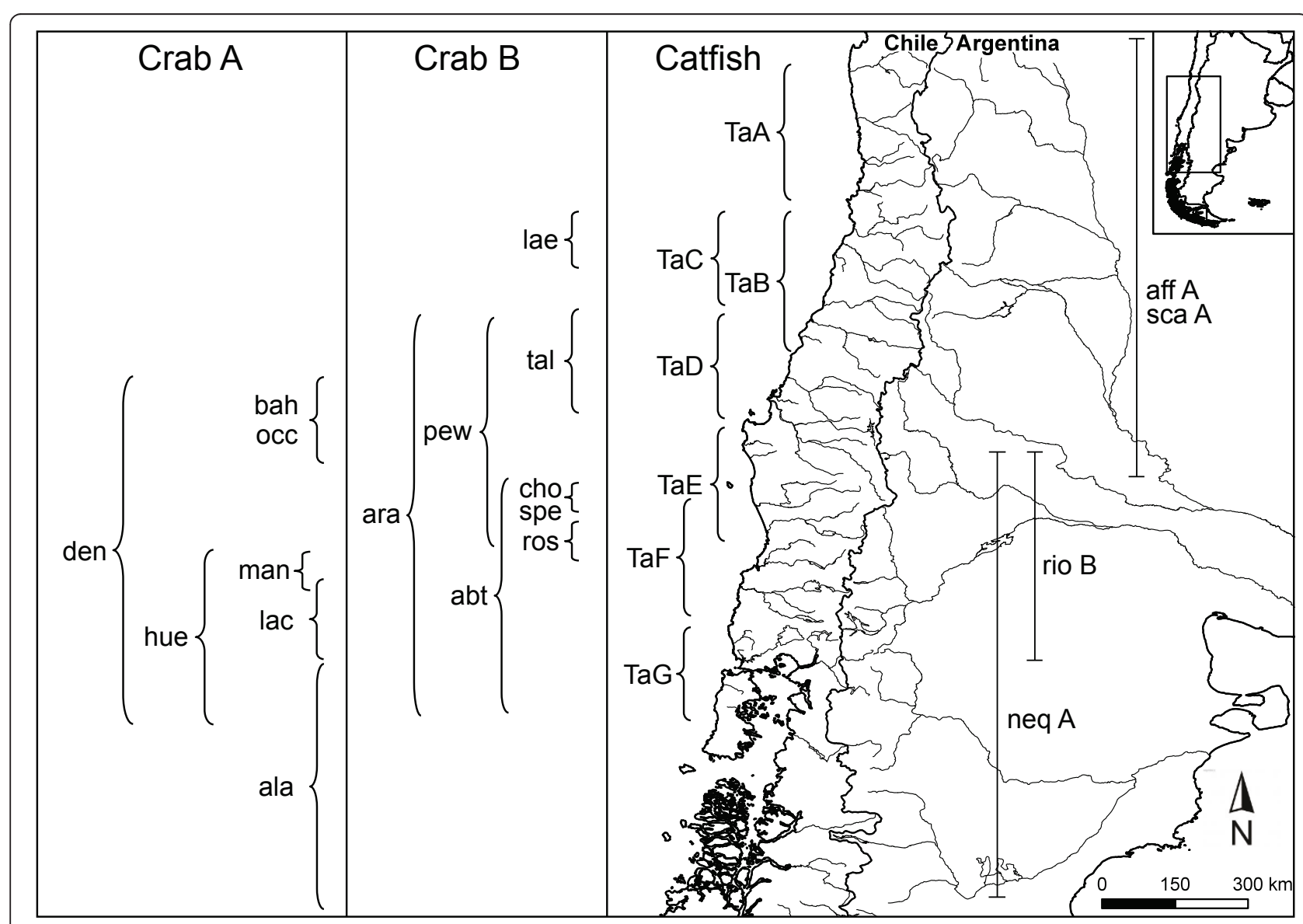

Figure 1 Map of South America showing major river systems of Chile and Argentina and distributions of Aegla taxa and Trichomycterus areolatus clades. 
example, genetic distance between two rivers, Río Maipo and Río Maule, are $2.6-2.8 \%$ and $2.0-2.8 \%$ in Aegla laevis and Trichomycterus areolatus respectively. In addition, genetic distances between codistributed sister-lineages are similar. For example, sister-clades (phylogroups: D + E: Figure 2) in Trichomycterus areolatus and sister-taxa Aegla bahamondei + A. occidentalis have overlapping divergence values of $1.0-2.3 \%$ and $1.7 \%$ respectively. Two codistributed phylogroups in Trichomycterus areolatus (clades F + G) and within Aegla abtao have similar, but non-overlapping, divergence values of $3.3-4.8 \%$ and 2.4 $3.2 \%$ respectively (see [13] for further discussion). Similar levels of genetic distance between contemporary lineages suggest these taxa may have been influenced by the same events. Finally both taxa are codistributed and often sympatric in the region suggesting both may have been similarly affected by the abiotic events that have shaped the region [13,20-23].

In this study we test the hypothesis of codivergence between Aegla species and Trichomycterus phylogroups. In other words, are the same historical events documented in the region responsible for generating the nearly identical levels of genetic divergence observed in these taxa? Four major geological and climate events may have played a role in shaping the evolutionary history of these taxa. First, the establishment of freshwater systems in the region that were precursors to current day drainages, some nine million years ago (Ma), may have driven initial lineage splitting $[12,21]$. Second, two dramatic fluctuations in sea-levels ( 5.0 Ma and $\sim 2.0 \mathrm{Ma}$ : [24]) documented in the region might have altered cladogenic rates. Finally, the relatively high amplitude climate oscillations experienced during the last million years of the Pleistocene might have increased or decreased speciation rates $[25,26]$. We generate specific predictions on the type of diversification models expected based on the impact of these abiotic events (Table 1). Furthermore we predict that if these shared events shaped genetic patterns across codistributed taxa, we expect to detect identical cladogenic rates and similar dates of lineage splitting in Aegla and Trichomycterus. To this end we examine the fit of six models of diversification to the catfish and crab phylogenies. In addition, we determined splitting times for major nodes. We reject the hypothesis of codivergence if both models of diversification and times of divergence differ across taxa.

\section{Results}

\section{Dates of cladogenic events}

We found that our three taxonomic groups originated during different time periods (Table 2 and Figure 2). Cladogenesis within Trichomycterus areolatus was initiated roughly 2.25 Ma (Late Miocene - Early Pliocene) some
1.7 - 2.8 million years after the basal divergences observed in both Aegla clades. The 95\% highest posterior density (HPD) of the basal Aegla nodes are consistant with episodes of increased sea levels documented at the Bay of Tongoy, Chile ( 4.2 - 5.0 Ma; [24]), whereas the basal node of Trichomycterus areolatus emerge during a time of decreased sea levels that occurred in the region roughly $1.4-2.2 \mathrm{Ma}$ [24]. Both crab phylogenies date to the Pliocene with AeglaA basal divergence occurring most recently (3.95 Ma), whereas AeglaB originated 5.05 Ma. Moreover, the majority of cladogenic events (15/19) in the crab phylogenies date to the Pliocene or Early Pleistocene (> $1 \mathrm{Ma})$. Only three cladogenic events, (AeglaA: node H; AeglaB: node J and K) occurred during the especially high amplitude climate cycles of the last 1 million years. All but one of the six cladogenic events in Trichomycterus areolatus occurred during the Pleistocene, with two events consistent with the high amplitude climate cycles of the last $1 \mathrm{Ma}$. Overall only five of the twenty-five cladogenic events events occurred during the last $1 \mathrm{Ma}$

Effective sample sizes for node estimates were over 500 (as were most parameters); thus, we assume the results are from thoroughly sampled analyses. Models selected using AIC for Trichomycterus areolatus were GTR + I + R, HKY + I, and HKY for cyt- $b$, gh, and rag1 respectively. The GTR $+\mathrm{I}+\mathrm{R}$ model provided the best fit for both $28 \mathrm{~S}$ and mitochondrial loci for both of the Aegla datasets. Nuclear mutation rates estimated from the analyses are as follows: Trichomycterus areolatus $\left(\mathrm{rag} 1=4.48 \times 10^{-4}\left[2.34 \times 10^{-4}-6.79 \times 10^{-4}\right]\right.$ and gh $\left.=1.24 \times 10^{-3}\left[7.41 \times 10^{-4}-1.81 \times 10^{-3}\right]\right)$, AeglaA $\left(28 \mathrm{~S}=1.63 \times 10^{-3}\left[7.25 \times 10^{-4}-2.58 \times 10^{-3}\right]\right.$, Aegla $\mathrm{B}$ $\left(28 \mathrm{~S}=1.04 \times 10^{-3}\left[5.38 \times 10^{-4}-1.60 \times 10^{-3}\right]\right.$.

\section{Diversification tests}

The best-fitting model of diversification (Table 3 ) for Trichomycterus was pure-birth (delta AICrc $=1.36, \mathrm{p}=$ 0.21 ), whereas the logistic density dependent model provided the best fit for AeglaA (delta AICrc $=7.79, \mathrm{p}=$ 0.02). A rate-variable birth-death (rvbd) model was the best model for AeglaB (delta AICrc $=5.47, \mathrm{p}=0.03$ ).

\section{Discussion}

This study was motivated by the observation of similar levels of genetic distances between lineages in three clades that are codistributed in freshwater systems of Chile. Our goal was to determine if this pattern was the result of codivergence driven by historical abiotic events. We discuss the temporal origins of the three groups. Then we discuss results of diversification tests and mechanisms that are postulated to have shaped this assemblage of freshwater taxa. 


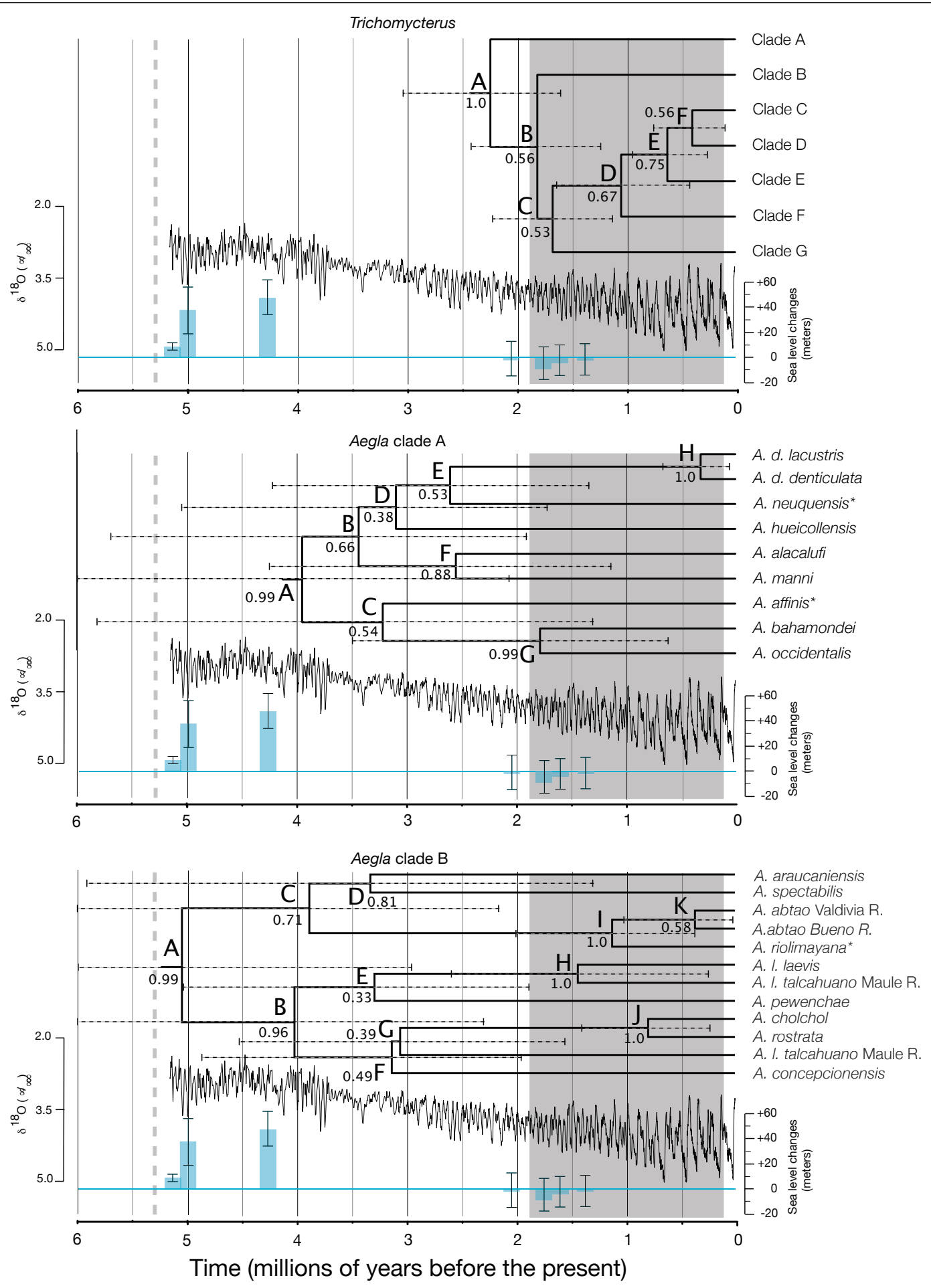

Figure 2 Species trees of three Chilean freshwater taxa, climate change and major episodes of sea level changes documented over the last 6 million years. Sea level changes (in blue, with max/min-bars) estimated from the Bay of Tongoy, Chile (Figure 1;[24]). Jagged lines indicate climate change inferred from benthic $\delta^{18} \mathrm{O}$ obtained from 57 globally distributed sites [25]. Pleistocene period indicated with gray background. Lower boundary of the Miocene epoch showed with a vertical dashed line. Species of Aegla with asterisks occur in Argentina. Letters refer to nodes discussed in the text and table 1. Posterior probabilities for nodes are below or next to node labels. Horizontal dashed lines are the 95\% HPD estimates of the node dates. 
Table 1 Hypothesized outcomes on cladogenic rates caused by major geological and climatic events documented in the region

\begin{tabular}{|c|c|c|c|}
\hline Abiotic event & $\begin{array}{l}\text { Time } \\
\text { period }\end{array}$ & Predictions and expectations & Reference \\
\hline $\begin{array}{l}\text { Establishment of freshwater systems } \\
\text { in Chile }\end{array}$ & $\sim 9.0 \mathrm{Ma}$ & $\begin{array}{l}\text { Origins and initial diversification } \\
\text { Basal nodes date to this period }\end{array}$ & {$[12,21]$} \\
\hline Dramatic increase in sea-levels & $4.3-5.3 \mathrm{Ma}$ & $\begin{array}{l}\text { Increased cladogenic events } \\
\text { Significant shifts in cladogenic rates (Yule two rate or rate-variable birth-death) }\end{array}$ & {$[24]$} \\
\hline Dramatic decrease in sea-levels & $1.4-2.2 \mathrm{Ma}$ & $\begin{array}{l}\text { Decreased cladogenic events } \\
\text { Significant shifts in cladogenic rates (Yule two rate or rate-variable birth-death) }\end{array}$ & {$[24]$} \\
\hline $\begin{array}{l}\text { Late Pleistocene climate oscillations } \\
\text { (Driver of speciation) }\end{array}$ & $1.0-0.1 \mathrm{Ma}$ & $\begin{array}{l}\text { Increase in cladogenic events } \\
\text { Majority of cladogenic events date to this period } \\
\& \\
\text { Significant shifts in cladogenic rates (Yule two rate or rate-variable birth-death) }\end{array}$ & {$[25,26]$} \\
\hline $\begin{array}{l}\text { Late Pleistocene climate oscillations } \\
\text { (Increased extinction) }\end{array}$ & $1.0-0.1 \mathrm{Ma}$ & $\begin{array}{l}\text { Decline in cladogenic rates } \\
\text { Few cladogenic events date to this period } \\
\& \\
\text { Decline in cladogenic rates (density dependent model [logistic or exponential] of } \\
\text { diversification) }\end{array}$ & {$[25-27,53]$} \\
\hline No impact & Throughout & $\begin{array}{l}\text { No change in cladogenic rates } \\
\text { Constant cladogenesis models: yule pure-birth or pure-birth }\end{array}$ & \\
\hline
\end{tabular}

\section{Temporal origins}

Lineage splitting time (mean) estimates of basal nodes vary considerably $(2.18-4.50 \mathrm{Ma})$, suggesting different processes generated initial cladogenesis (Table 2 and Figure 2). The confidence intervals of the two crab groups overlap considerably, suggesting similar temporal origins. However, different models of cladogensis were recovered for these two groups suggesting different processes have shaped these two groups (see next section). The hypothesis that the original formation of river systems in the region some $9 \mathrm{Ma}[12,21]$ played a role in shaping this fauna is rejected. However the exceptionally high sea levels that occurred from 5.0 to 4.2 Ma are consistent with the origins of both Aegla clades (Table 2 and Figure 2; [24]). Cladogenesis within Trichomycterus areolatus occurred relatively recently $(\sim 2.25 \mathrm{Ma})$ and is

Table 2 Estimates of the ages of major nodes in the Trichomycterus areolatus and Aegla phylogenies (Figure 2)

\begin{tabular}{cccc}
\hline Node & Trichomycterus & Aegla A & Aegla B \\
\hline A & $2.25(1.54-3.09)$ & $3.95(2.16-6.56)$ & $5.05(2.94-7.84)$ \\
B & $1.82(1.23-2.43)$ & $3.44(1.83-5.70)$ & $4.02(2.33-6.17)$ \\
C & $1.68(1.15-2.24)$ & $3.22(1.39-5.78)$ & $3.89(2.17-6.09)$ \\
D & $1.05(\mathbf{0 . 4 5}-1.66)$ & $3.10(1.58-5.11)$ & $3.33(1.36-5.81)$ \\
E & $\mathbf{0 . 6 2 ( 0 . 3 6 - 0 . 9 2 )}$ & $2.60(1.33-4.23)$ & $3.30(1.80-5.07)$ \\
F & $\mathbf{0 . 3 9}(\mathbf{0 . 2 1 - 0 . 6 1 )}$ & $2.55(1.17-4.23)$ & $3.13(1.61-4.81)$ \\
G & & $1.78(\mathbf{0 . 6 2}-3.50)$ & $3.06(1.94-4.57)$ \\
H & & $\mathbf{0 . 3 2}(\mathbf{0 . 0 7}-\mathbf{0 . 6 3})$ & $1.44(\mathbf{0 . 3 7}-2.62)$ \\
I & & & $1.12(\mathbf{0 . 3 2}-2.03)$ \\
J & & & $\mathbf{0 . 7 9}(\mathbf{0 . 2 4}-1.36)$ \\
K & & & $\mathbf{0 . 3 7}(\mathbf{0 . 0 1}-1.07)$ \\
\hline
\end{tabular}

Mean estimates and 95\% HPD are given in millions of years before present. Values in bold fall within the last $1 \mathrm{Ma}$, italics designates dates that are Miocene origin, all others are Pliocene or Early Pleistocene (> $1 \mathrm{Ma})$ origin. consistent with a period of low sea levels. This time period is also consistent with the second set of cladogenic events observed within AeglaB. The majority of cladogenic events within $T$. areolatus appear in the Pleistocene with the last two events dating to a period $(<1$ Ma) of high amplitude climate oscillations (Table 2 and Figure 2). Only three cladogenic events occurred during the last $1 \mathrm{Ma}$ in the two crab clades. The relatively few cladogenic events observed during the last $1 \mathrm{Ma}$ reject the hypothesis that the especially high amplitude climate cycles of this period played a significant role in driving cladogensis within these taxa [26].

\section{Models and mechanisms of cladogenesis}

Three different models of diversification were supported rejecting the hypothesis of codivergence among taxa. The pure birth model of diversification best explains cladogenesis within Trichomycterus areolatus and suggests that the rate initiated in this taxon was maintained throughout its evolutionary history and argues against any significant impact on rates by later sea-level changes or climate oscillations. A density-dependent model of declining diversification is the best explanation of cladogenesis in AeglaA.

Declines in diversification rates can occur for several reasons, but are most notable in adaptive radiations $[27,28]$. Speciation rates can decline as available niches become filled with the accumulation of species [29] or if an underparameterized model of molecular evolution is employed [30]. The molecular models employed in this study are relatively complex suggesting the rate decline is not an artifact of the analysis. Alternatively, the rate decline could be due to increased extinction rates.

To our knowledge, no empirical data exist on population sizes in Aegla, thus we can only make broad assumptions 
Table 3 Results of maximum likelihood tests of diversification models

\begin{tabular}{llll}
\hline Taxon & Best constant model & Best variable model & $\Delta$ AICrc \\
\hline Trichomycterus & pure birth (AIC $=5.82)$ & DDL (AIC $=4.47)$ & $1.36(\mathrm{p}=0.21)$ \\
Aegla A & pure birth (AIC $=12.56)$ & DDL (AIC $=4.77)$ & $7.79(\mathrm{p}=0.02)$ \\
Aegla B & pure birth (AIC $=11.79)$ & rvbd (AIC $=\mathbf{6 . 3 2})$ & $5.47(\mathrm{p}=0.03)$ \\
\hline
\end{tabular}

Shown are best constant and best variable rate models selected from six candidate models. Tests of significance were conducted by simulating 5000 phylogenies under a constant birth-death model. The best constant model was rejected if the $\Delta$ AICrc was significant (two-tailed alpha $=0.05,[49]$ ). DDL is a logistic density dependent model and rvbd is a rate-variable birth-death model. The best-fitting model is in bold.

on the relative sizes of populations and their susceptibility to extinction. The distributions of several species of Chilean Aegla are restricted to single or several adjoining river system suggesting small populations [19]; Figure 1). Restricted and fragmented distributions coupled with small isolated populations in some species [16] suggest that population sizes are small, possibly increasing the risk of extinction [31]. In addition, population sizes, inferred from estimates of genetic diversity, are low and declining in one crab species, Aegla alacalufi [16].

Alternatively, especially high amplitude climate cycles over the last one million years may have increased extinction. Only one lineage splitting event dates to the Late Pleistocene (<1 Ma) rejecting the hypothesis that this period was a driver of speciation. Rather the decline in diversification suggests that the Late Pleistocene climate cycles, or the lowered sea levels of $\sim 2 \mathrm{Ma}$, may have inhibited speciation or increased extinction within AeglaA. A phylogeographic study of Aegla alacalufi recovered deeper divergence between non-glaciated populations than between glaciated populations [16]. Many of the drainage systems inhabited by Chilean Aegla species were covered at least partially by ice during the last and presumably previous glacial cycles $[13,16]$. It is likely then that repeated glacial cycles coupled with small population sizes in many Aegla species inhibited diversification by increasing extinction rates.

The rate-variable model best explains diversification in AeglaB and suggests that this clade experienced a more dynamic evolutionary history than the other clades. That is the onset of cladogenesis initiated approximately $5 \mathrm{Ma}$ were later altered by abiotic events. A second cluster of cladogenic events begins $1.44 \mathrm{Ma}$ (node $\mathrm{H}$ ) which is a time consistent with both lowered sea levels and the onset of high amplitude glacial cycles, suggesting that these these events increased diversification. Thus in contrast to AeglaA and Trichomycterus areolatus this period is postulated to be a driver of cladogenesis in AeglaB.

\section{Tests of codivergence}

Historical approaches have been used extensively in the study of codivergence in host-parasite systems [32]. For example, the assumption that pattern equaled process in hantavirus was assumed because the virus phylogeny formed three primary clades that coincided with the three rodent subfamilies that formed their hosts and the fact that there is a high degree of host specificity in the system [33]. However, [33] were able to reject the hypothesis of codivergence between the hantavirus virus and their mammalian hosts.

In this study historical methods were employed to determine if abiotic events were possibly responsible for driving diversification in these clades, which in turn allows us to test the hypothesis of codivergence. The observation of similar levels of genetic distance between major lineags among these taxa suggests that they are the result of either shared evolutionary or ecological processes. Our study illustrates the important role that history can play in shaping current patterns and argues against assuming that the observation of similar patterns among codistributed taxa equals a shared history [9]. It remains to be determined how, if any, ecological interactions have shaped this species assemblage.

Employing phylogeographic and phylogenetic methods to test hypotheses of codivergence among contemporary faunas is an exciting and developing research area [34]. A fundamental challenge in this endeavor will be choosing methods that can tease apart complex evolutionary histories among taxa. In this paper we employed two different methods to test the hypothesis of codivergence among our three focal groups. Obviously there are some caveats with these methods. For example, confidence intervals on divergence dates are wide and in some cases overlap multiple abiotic events and divergence times from the other taxa. Relying on this method alone would not have allowed us to test our hypothesis. However, differences in timing of lineage splitting combined with the fact that we observed three taxon specific models of cladogenesis allows us to reject the hypothesis of codivergence. Another potential problem arises by using mutation rates that are not taxon specific. This is an issue for most comparative molecular studies due to the paucity of taxon specific rates. Because mutation rates vary widely across taxa - vertebrates versus invertebrates in our study - assuming a common rate is an unacceptable solution. Finally we recognize our relatively taxon poor phylogenies may make it difficult to rigorously compare models of diversification [27,35]. For example missing or undiscovered taxa could cause an increase, decrease or shift in diversification rates. The previous phylogeographic and phylogenetic studies of these two taxa 
did recover undescribed independently-evolving lineages and these were included in this study. Despite these caveats our study illustrates the potential to test codivergence among codistributed fauna when multiple approaches are employed [34,36-39]

\section{Conclusions}

Results from two different methodological approaches reject the hypothesis of codivergence among our three focal groups. Rather these representatives of the Chilean freshwater assemblage evolved through temporally-independent processes. Although this freshwater fauna is relatively depauperate additional taxa need to be studied to determine if this is a pervasive observation in freshwater systems of Chile and how ecological interactions are currently operating on the entire species assemblage. This study illustrates the importance of using historical methods to test hypotheses on how contemporary patterns have been formed and cautions against assuming that congruent patterns are the result of shared processes or ecological interactions alone.

\section{Materials and methods}

\section{Chilean taxa and molecular data}

The catfish Trichomycterus areolatus and 21 species of Aegla crabs were studied from the southern temperate freshwater river systems of Chile (Figure 1). Trichomycterus areolatus is an abundant and widespread freshwater fish with broad ecological tolerances [13]. Data for Trichomycterus areolatus are the mitochondrial cytochrome $b$ gene (1137 base-pairs, [bp] GenBank accession numbers FJ772091 - FJ772237) and two newly obtained nuclear loci (growth hormone [1491 bp: JN186609 - JN186714] and rag1 [992 bp: JN186409 - JN186531]) from 63 individuals comprising seven clades [13]. Like the catfish, Chilean Aegla crabs are widely distributed and occur in a variety of freshwater habitats [23]. Two non-sister clades of mostly Chilean Aegla species were examined [19,23]. The first clade, hereafter referred to as AeglaA, includes nine taxa, the second, AeglaB, consists of twelve taxa [23]. Molecular data for Aegla consisted of the cytochrome oxidase I and II genes (1598 bp: AY049985-050166) and the nuclear $28 \mathrm{~S}$ gene (3105 bp: AY595931 - AY595973, AY596092 AY596093), and 20 and 24 individuals from AeglaA and AeglaB, respectively [19,20,23].

\section{Phylogeny and dating}

The best-fitting model of molecular evolution for each locus was determined using the Akaike Information Criterion (AIC) in jModeltest [40]. A species tree and dates of major nodes were estimated simultaneously using *BEAST [41] as implemented in Beast 1.6.1 [42]. A Yule tree prior, piecewise linear and constant-root population size model and lognormal molecular clock were assumed. Analyses were run $5.0 \times 10^{7}$ generations with a burn-in of $10 \%$ [43]
We assumed a mitochondrial mutation rate of $1.0 \times 10^{-8}$ [44], and a range of $8.3 \times 10^{-9}-1.3 \times 10^{-8}[45,46]$ for Trichomycterus areolatus and Aegla, respectively. Mutation rates for all nuclear markers were estimated, relative to the mitochondrial rate, using a normal prior. Due to uncertainty in the appropriate outgroup a midpoint root was used to root the Trichomycterus areolatus phylogeny [13]. Two individuals of Aegla papudo (cytochrome I: AY050077 - AY050078; cytochrome II: AY050121AY050121; 28S: AY595929 - AY595930) were used to root the Aegla phylogeny [19,20,23]. Mean divergence estimates in millions of years and their 95\% confidence intervals were obtained for all nodes using TRACER v1.4 [47]. If dates of major nodes or their confidence intervals overlap with abiotic events (i.e., sea level changes; Table 1), we assume those events may have been responsible for driving divergence at those nodes [48].

\section{Tests of diversification models}

The hypothesis of codivergence predicts the same process of cladogenesis should be observed across taxa. To this end we evaluate the fit of six explicit models of diversification to each of the three phylogenies using a maximum likelihood test implemented in LASER [49]. In general, these models provide the means to determine if cladogenic rates were altered (i.e. by abiotic events), or remained constant (no effect), during the phylogenetic history of each group. If these taxa codiverged, due to shared historical events, we expect each to have evolved under the same model. The six models compared were: Yule pure-birth, birth-death, logistic density-dependent, exponential density-dependent, Yule two-rate, and a rate-variable birthdeath model. These models capture expected patterns of cladogenesis under various historical scenarios (Table 1). For example, if changes in Pliocene sea levels altered rates, we expect to observe an instantaneous shift in rates. Similarly, we would observe a shift in rates if Late Pleistocene climate change increased lineage splitting. Under these two scenarios, we expect to observe either a Yule two-rate or rate-variable birth-death model. In contrast, if Late Pleistocene climate change decreased diversification, through increased extinction or decreased speciation, we would expect to detect either a logistic or exponential density dependent model. Finally, constant models (Yule purebirth or birth-death) are the expected outcome if climate and sea level changes had no impact on speciation rates (pure-birth and birth-death models assume no extinction has occurred). The best constant (RC) and best rate variable (RV) model were determined using (AIC). Delta $\operatorname{AICrc}\left(=\mathrm{AIC}_{\mathrm{RC}}-\mathrm{AIC}_{\mathrm{RV}}\right)$ was used as a test statistic. Significance of each delta AICrc was determined using null distributions derived from 5,000 trees simulated under a constant birth-death (extinction = lineage splitting) model (two-tailed alpha $=0.05,[49])$. 
Our objective in this study was to investigate processes of cladogenesis in codistributed taxa with similar genetic distances between evolutionarily distinct lineages. Unmack et al [13] phylogeographic study of Trichomycterus areolatus recovered seven well-supported terminal clades with little to no geographical overlap between them. These clades had model-corrected sequence divergences between them greater than many recognized species (> 2\%: e.g. $[11,50])$. These observations qualify the seven clades as evolutionarily distinct lineages under several concepts including evolutionarily significant units (ESU: [51]) and the phylogenetic species concept [52]. Therefore, we recognized each of the seven clades recovered in Trichomycterus areolatus as taxonomically equivalent to the currently recognized species as well as several recently discovered lineages in Aegla.

\section{Acknowledgements \\ This work was funded by a grant from the U.S. National Science Foundation (NSF) PIRE program (OISE 0530267) to support collaborative research on Patagonian Biodiversity among the following institutions (listed alphabetically): Brigham Young University, Centro Nacional Patagónico (AR), Dalhousie University, Instituto Botánico Darwinion (AR), Universidad Austral de Chile, Universidad Nacional del Comahue, Universidad de Concepción, and George Washington University.}

\section{Author details}

${ }^{1}$ Evolutionary Ecology Laboratories, Department of Biology, Brigham Young University, Provo, UT 84602 USA. ${ }^{2} \mathrm{CIBIO}$, Centro de Investigação em Biodiversidade e Recursos Genéticos, Universidade do Porto, Campus Agrário de Vairão, 4485-661 Vairão, Portugal. ${ }^{3}$ Monte L. Bean Life Science Museum, Brigham Young University, Provo, UT 84602 USA.

\section{Authors' contributions}

BRB and JBJ conceived the study. BRB conducted analyses and wrote the paper. BRB and PJU created figures. PJU, MPL, KAC and JBJ generated data. All authors read and approved the final manuscript.

Received: 29 March 2011 Accepted: 25 November 2011

Published: 25 November 2011

\section{References}

1. MacArthur RH, Wilson EO: The theory of island biogeography. Princeton, N.J.:: Princeton University Press; 1967.

2. Hubbell SP: The unified neutral theory of biodiversity and biogeography. Princeton [N.J]: Princeton University Press; 2001.

3. Wiens JJ, Donoghue MJ: Historical biogeography, ecology and species richness. Trends Ecol Evol 2004, 19(12):639-644.

4. Lee JB, Johnson JB: Biogeography of the livebearing fish Poecilia gillii in Costa Rica: are phylogeographical breaks congruent with fish community boundaries? Mol Ecol 2009, 18(19):4088-4101.

5. Burridge CP, Craw D, Waters JM: River capture, range expansion, and cladogenesis: the signature of freshwater vicariance. Evolution 2006, 60(5):1038-1049

6. Hewitt G: The genetic legacy of the Quaternary ice ages. Nature 2000, 405(6789):907-913.

7. Rosen DE: Vicariant Patterns and Historical Explanation in Biogeography. Syst Biol 1978, 27(2):159-188.

8. Cavender-Bares J, Kozak KH, Fine PVA, Kembel SW: The merging of community ecology and phylogenetic biology. Ecol Lett 2009, 12(7):693-715.

9. Johnson MTJ, Stinchcombe JR: An emerging synthesis between community ecology and evolutionary biology. Trends Ecol Evol 2007, 22(5):250-257.
10. Nelson GJ, Platnick Nl: Systematics and biogeography: cladistics and vicariance. New York: Columbia University Press; 1981.

11. Avise JC: Phylogeography: the history and formation of species. Cambridge, Mass: Harvard University Press; 2000.

12. Potter PE: The Mesozoic and Cenozoic paleodrainage of South America: a natural history. Journal of South American Earth Sciences 1997, 10(5-6):331-344.

13. Unmack PJ, Bennin AP, Habit EM, Victoriano PF, Johnson JB: Impact of ocean barriers, topography, and glaciation on the phylogeography of the catfish Trichomycterus areolatus (Teleostei: Trichomycteridae) in Chile. Biol J Linn Soc 2009, 97(4):876-892.

14. Beheregaray LB: Twenty years of phylogeography: the state of the field and the challenges for the Southern Hemisphere. Mol Ecol 2008, 17(17):3754-3774.

15. Ruzzante DE, Walde SJ, Cussac VE, Dalebout ML, Seibert J, Ortubay S, Habit E: Phylogeography of the Percichthyidae (Pisces) in Patagonia: roles of orogeny, glaciation, and volcanism. Mol Ecol 2006, 15(10):2949-2968.

16. Xu J, Perez-Losada M, Jara CG, Crandall KA: Pleistocene glaciation leaves deep signature on the freshwater crab Aegla alacalufi in Chilean Patagonia. Mol Ecol 2009.

17. Balian EV, Lévêque C, Segers H, Martens K: Freshwater Animal Diversity Assessment. 2008, 198.

18. Dyer B: Systematic review and biogeography of the freshwater fishes of Chile. Estudios Oceanológicos 2000, 19:77-98.

19. Perez-Losada M, Bond-Buckup G, Jara CG, Crandall KA: Conservation Assessment of Southern South American Freshwater Ecoregions on the Basis of the Distribution and Genetic Diversity of Crabs from the Genus Aegla. Conserv Biol 2009.

20. Pérez-Losada M, Jara CG, Bond-Buckup G, Crandall KA: Phylogenetic relationships among the species of Aegla (Anomura: Aeglidae) freshwater crabs from Chile. Journal of Crustacean Biology 2002, 22(2):304-313.

21. Lundberg JG, Marshall $L G, J G$, Horton $B, L$ MMCS, F W: The stage for Neotropical fish diversification: A history of tropical South American river. Porto Alegre, Brazil: EDIPUCRS; 1998.

22. Perez-Losada M, Bond-Buckup G, Jara CG, Crandall KA: Molecular systematics and biogeography of the southern South american freshwater "crabs" Aegla (decapoda: Anomura: Aeglidae) using multiple heuristic tree search approaches. Syst Biol 2004, 53(5):767-780.

23. Pérez-Losada M, Jara CG, Bond-Buckup G, Crandall KA: Conservation phylogenetics of Chilean freshwater crabs Aegla (Anomura, Aeglidae): assigning priorities for aquatic habitat protection. Biol Conserv 2002, 105(3):345-353.

24. Le Roux JP, Olivares DM, Nielsen SN, Smith ND, Middleton H, Fenner J, Ishman SE: Bay sedimentation as controlled by regional crustal behaviour, local tectonics and eustatic sea-level changes: Coquimbo Formation (Miocene-Pliocene), Bay of Tongoy, central Chile. Sedimentary Geology 2006, 184(1-2):133-153.

25. Lisiecki LE, Raymo ME: A Pliocene-Pleistocene stack of 57 globally distributed benthic $\delta^{18} \mathrm{O}$ records. Paleoceanography 2005, 20(1):1-17.

26. Zink RM, Klicka J, Barber BR: The tempo of avian diversification during the Quaternary. Philos T Roy Soc B 2004, 359(1442):215-219.

27. Phillimore AB, Price TD: Density-dependent cladogenesis in birds. Plos Biol 2008, 6(3):e71.

28. Schluter D: The ecology of adaptive radiation/Dolph Schluter. Oxford: Oxford University Press; 2000

29. McPeek MA: The ecological dynamics of clade diversification and community assembly. Am Nat 2008, 172(6):E270-284.

30. Revell $\amalg$, Harmon $\sqcup$, Glor RE: Underparameterized model of sequence evolution leads to bias in the estimation of diversification rates from molecular phylogenies. Syst Biol 2005, 54(6):973-983.

31. Newman D, Pilson D: Increased probability of extinction due to decreased genetic effective population size: experimental populations of Clarkia Pulchella. Hoboken, NJ, ETATS-UNIS: Wiley; 199751.

32. Page RDM, Charleston MA: Trees within trees: phylogeny and historical associations. Trends Ecol Evol 1998, 13(9):356-359.

33. Ramsden C, Holmes EC, Charleston MA: Hantavirus Evolution in Relation to Its Rodent and Insectivore Hosts: No Evidence for Codivergence. $\mathrm{Mol}$ Biol Evol 2009, 26(1):143-153. 
34. Hickerson MJ, Carstens BC, Cavender-Bares J, Crandall KA, Graham CH, Johnson JB, Rissler L, Victoriano PF, Yoder AD: Phylogeography's past, present, and future: 10 years after Avise, 2000. Mol Phylogenet Evol 2010, 54(1):291-301.

35. Ricklefs RE: Estimating diversification rates from phylogenetic information. Trends Ecol Evol 2007, 22(11):601-610.

36. Barber BR, Klicka J: Two pulses of diversification across the Isthmus of Tehuantepec in a montane Mexican bird fauna. P Roy Soc B-Biol Sci 2010, 277(1694):2675-2681.

37. Carnaval AC, Hickerson MJ, Haddad CF, Rodrigues MT, Moritz C: Stability predicts genetic diversity in the Brazilian Atlantic forest hotspot. Science 2009, 323(5915):785-789.

38. Templeton AR: Out of Africa again and again. Nature 2002, 416(6876):45-51.

39. Templeton AR: Statistical hypothesis testing in intraspecific phylogeography: nested clade phylogeographical analysis vs. approximate Bayesian computation. Mol Ecol 2009, 18(2):319-331.

40. Posada D: jModelTest: Phylogenetic Model Averaging. Mol Biol Evol 2008 25(7):1253-1256

41. Heled J, Drummond AJ: Bayesian inference of species trees from multilocus data. Mol Biol Evol 27(3):570-580.

42. Drummond AJ, Rambaut A: BEAST: Bayesian evolutionary analysis by sampling trees. Bmc Evol Biol 2007, 7:214

43. Drummond AJ, Ho SY, Phillips MJ, Rambaut A: Relaxed phylogenetics and dating with confidence. Plos Biol 2006, 4(5):e88.

44. Near TJ, Benard MF: Rapid allopatric speciation in logperch darters (Percidae: Percina). Evolution 2004, 58(12):2798-2808

45. Knowlton N, Weigt LA, Solorzano LA, Mills DK, Bermingham E: Divergence in proteins, mitochondrial DNA, and reproductive compatibility across the isthmus of Panama. Science 1993, 260(5114):1629-1632.

46. Schubart CD, Diesel $R$, Hedges SB: Rapid evolution to terrestrial life in Jamaican crabs. London, ROYAUME-UNI: Nature Publishing Group; 1998393.

47. Rambaut A, Drummond AJ: TRACER v1.4. 2007.

48. Lemmon EM, Lemmon AR, Cannatella DC, Brown J: Geological and climatic forces driving speciation in the continentally distributed trilling chorus frogs (Pseudacris). Evolution 2007, 61(9):2086-2103.

49. Rabosky DL: Likelihood methods for detecting temporal shifts in diversification rates. Evolution 2006, 60(6):1152-1164.

50. April J, Mayden RL, Hanner RH, Bernatchez L: Genetic calibration of species diversity among North America's freshwater fishes. Proceedings of the National Academy of Sciences 2011, 108(26):10602-10607.

51. Moritz C: Defining 'Evolutionarily Significant Units' for conservation. Trends Ecol Evol 1994, 9(10):373-375.

52. Cracraft J: Speciation and its ontology: the empirical consequences of alternative species concepts for understanding patterns and processes of differentiation. In Speciation and its Consequences. Edited by: Endler DOJA. Sinauer Associates; 1989:28-59.

53. Levinton JS: A theory of diversity equilibrium and morphological evolution. Science 1979, 204(4390):335-336.

doi:10.1186/1471-2148-11-343

Cite this article as: Barber et al:: Different processes lead to similar patterns: a test of codivergence and the role of sea level and climate changes in shaping a southern temperate freshwater assemblage. $B M C$ Evolutionary Biology 2011 11:343.

\section{Submit your next manuscript to BioMed Central and take full advantage of:}

- Convenient online submission

- Thorough peer review

- No space constraints or color figure charges

- Immediate publication on acceptance

- Inclusion in PubMed, CAS, Scopus and Google Scholar

- Research which is freely available for redistribution

Submit your manuscript at www.biomedcentral.com/submit
Ciomed Central 